\section{To: (Receiving Organization) \\ Distribution}

5. Proj./Prog./Dept./Div.:

Spent Nuclear Fuel Project

8. Originator Remarks:

For approval and release.

11. Receiver Remarks: 11A. Design Baseline Document? [] Yes [X] No
3. From: (Originating Organization) Numatec Hanford Corporation Sludge Treatment Project

6. Design Authority/ Design Agent/Cog. Engr.:

A. G. Westra
4. Related EDT No.:

NA

7. Purchase Order No.:

NA

9. Equip./Component No.:

NA

10. System/Bldg./Facility: NA

12. Major Assm. DHg. No.: NA

13. Permit/Permit Application No.: NA

14. Required Response Date:

NA

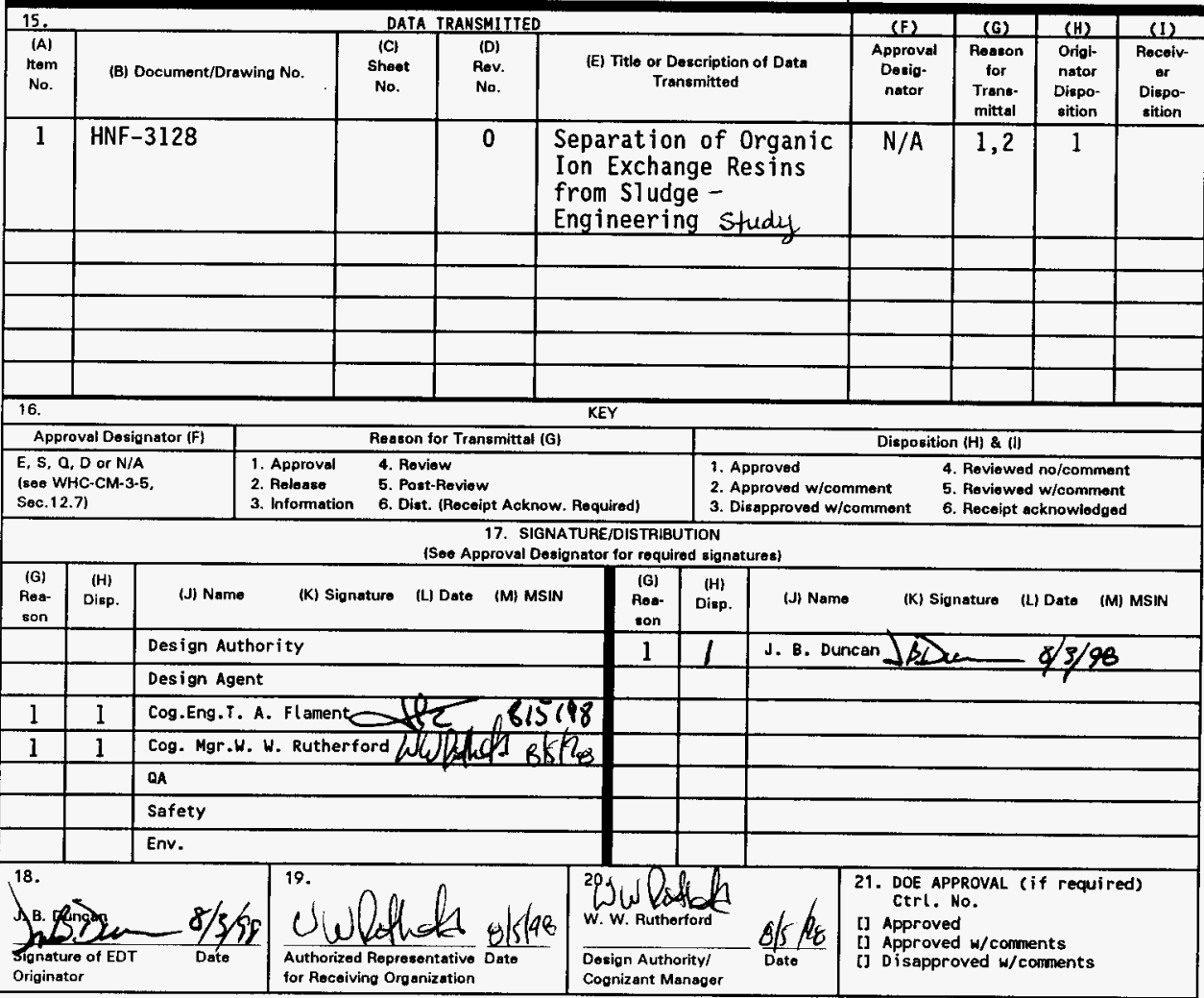


HNF-3128, Rev. 0

\title{
SEPARATION OF ORGANIC ION EXCHANGE RESINS FROM SLUDGE - ENGINEERING STUDY
}

\author{
J. B. Duncan \\ COGEMA Engineering Corporation \\ Richland, WA 99352 \\ U.S. Department of Energy Contract DE-AC06-96RL13200
EDT/ECN: $624548 \quad$ UC: 2000
Org Code: 8C700 Charge Code: LD45I HANA260O
B\&R Code: EW7040000 Total Pages: 28 \\ Key Words: Separations, Screening, Sedimentation, Flotation, \\ Elutriation
}

Abstract: This engineering study evaluates the use of physical separation technologies to separate organic ion exchange resin from KE Basin sludge prior to Nitric Acid dissolution. This separation is necessitate to prevent nitration of the organics in the acid dissolver. The technologies under consideration are: screening, sedimentation, elutriation. The recommended approach is to first screen the sludge and resin 300 microns then subject the 300 microns plus material to elutriation. The superficial velocity of the elutriation column will be adjusted to maximize the 1 ift of the jon exchange resins and minimize entrainment of sludge.

\footnotetext{
TRADEMARK DISCLAIMER. Reference herein to any specific commercial product, process, or service by trade name, trademark, manufacturer, or otherwise, does not necessarily constitute or imply its endorsement, recommendation, or favoring by the United States Government or any agency thereof or its contractors or subcontractors.
}

Printed in the United States of America. To obtain copies of this document, contact: Document Control Services, P.O. Box 950, Mailstop H6-08, Richland WA 99352, Phone (509) 372-2420; Fax (509) 376-4989.
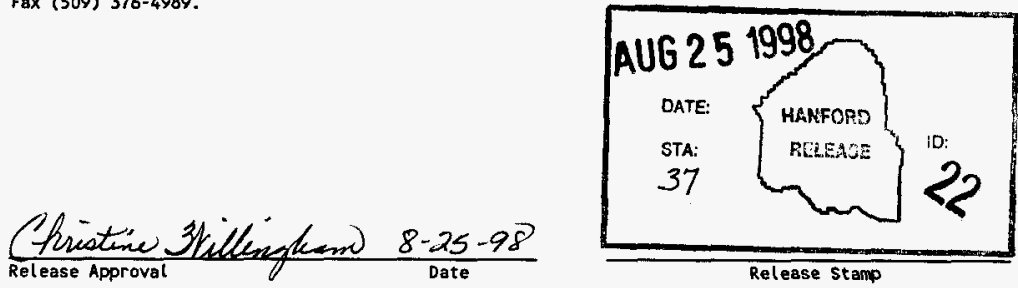

Approved for Public Release 


\title{
SEPARATION OF ORGANIC ION EXCHANGE RESINS FROM SLUDGE - ENGINEERING STUDY
}

\author{
HNF-3128
}

Rev. 0

August 1998 


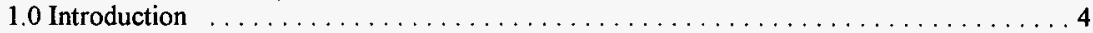

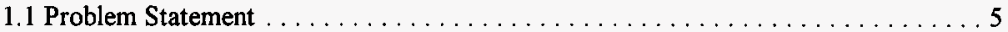

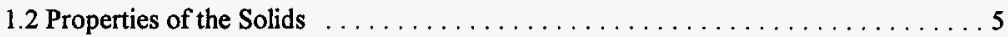

1.2.1 Particle Size . . . . . . . . . . . . . . . . . . . . . . 5

1.2.2 Particle Density . ......................... 7

1.2.3 Other Characteristics of the Solids . . . . . . . . . . . . . . . 7

1.2.4 Conclusions on the Solids Properties $\ldots \ldots \ldots \ldots \ldots \ldots \ldots \ldots$

2.0 Mechanisms and Technologies for Organic Ion Exchange Resins Separations . . . . . . . . 8

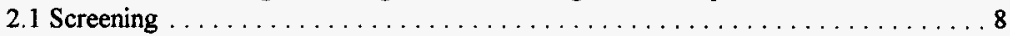

2.1.1 Applicability of Screening to the Separation between Sludge and Organic Ion Exchange Resins ...................... 10

2.1.2 Screening Technologies ....................... 10

2.1.3 Recommendation for Screening Technologies $\ldots \ldots \ldots \ldots \ldots \ldots 10$

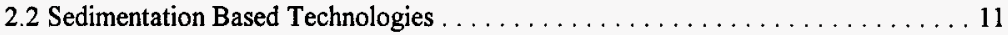

2.2.1 Gravity Sedimentation $\ldots \ldots \ldots \ldots \ldots \ldots \ldots \ldots \ldots \ldots \ldots \ldots$

2.2.2 Centrifugal Sedimentation ...................... 14

2.2.3 Recommendation for Sedimentation Based Technologies . . . . . . . . . 19

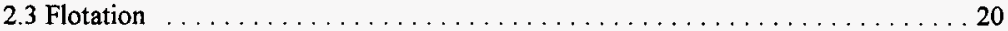

2.3.1 Flotation Mechanism ......................... 20

2.3.2 Applicability of Flotation . . . . . . . . . . . . . . . 20

3.0 Recommendation of a Separation Concept . . . . . . . . . . . . . . . 21

3.1 Separation Principle ................................ 21

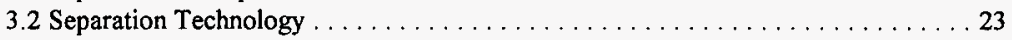

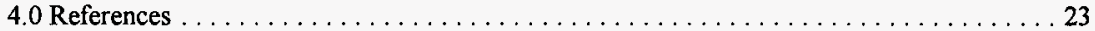

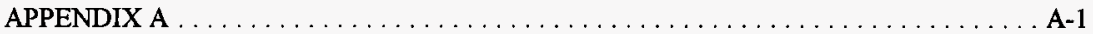




\section{LIST OF TABLES}

HNF-3128, Rev. 0

1-1 Densities of Compounds in the K East Basin Floor Sludge and Weasel Pit Sludge......... .7

2-1 Advantages and Drawbacks of Different Sedimentation Based Technologies.................19

\section{LIST OF FIGURES}

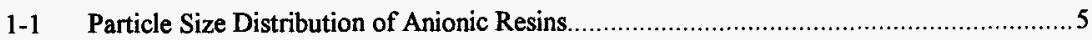

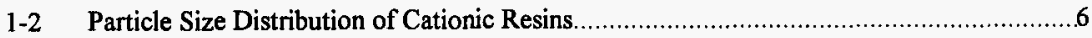

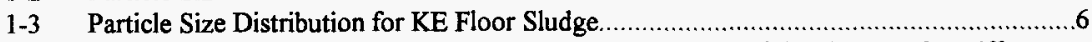

2-1 Variation of the Terminal Velocities as a Function of the Particle Diameter for Different Type of K Basin Solids........................................................................... 12

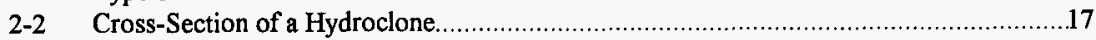

2-3 Classification of Centrifugal Sedimentation Equipment ..........................................18

3-1 Two Step Mechanism to Separate the Resins from the Other Solids...........................22

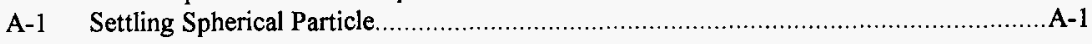


HNF-3128, Rev. 0

\subsection{Introduction}

The baseline process for the $\mathrm{K}$ Basin sludge disposal is chemical treatment followed by interim storage of liquids in Tank 241-AW-105 and disposal of solids in the Environmental Restoration Disposal Facility (ERDF). The ERDF is a Hanford Site landfill that meets the substantive Toxic Substance Control Act, Resource Conservation and Recovery Act and radioactive waste disposal requirements. Approximately $52 \mathrm{~m}^{3}$ of sludge are expected to require processing.

The proposed chemical process is initiated by collecting solids which pass a $6-\mathrm{mm}$ (1/4-inch) mesh screen from the basins. The materials passing the screen will be solubilized in nitric acid solution. The solution phase containing dissolved uranium and most of the radionuclides will be diluted with a solution of depleted uranium 235 (for criticality control), adjusted with iron for neutron absorption, neutralized with sodium hydroxide, and adjusted with sodium nitrite for corrosion control prior to storage in 241-AW-105. The solid phase will be stabilized (possibly by rinsing, leaching and grouting), packaged, and disposed at ERDF. Dissolution process off-gas will be treated and released to the atmosphere.

Characterization sampling undertaken in the K East and K West basins in 1995 and 1996 identified the presence of resins beads in different locations of the $\mathrm{K}$ East basin. Locations in which resin beads were observed are the:

- basin floor sludge (sample KE-H08),

- canister sludge (one canister), and

- weasel pit (composite sludge prepared for the dissolution tests).

Following these observations, it is estimated that over the course of operation, approximately 1.05 cubic meters nominal ( 3 cubic meters maximum) of Purolite NRW resin (mixed bed) may have been inadvertently introduced into the basin (Pearce 1998).

The presence of the resins require special consideration for sludge removal and processing. This document presents the results of an evaluation of methods for removing the resin beads from the sludge prior to acid digestion. 
HNF-3128, Rev. 0

\subsection{Problem Statement}

Preliminary tests performed by Pacific Northwest National Laboratory indicate two types of chemical reactions can occur between nitric acid and the Organic Ion Exchange Resins (OIER).

1 The resins are nitrated by nitric acid and a reactive compound is formed.

2. There is a plutonium and americium uptake by the resins that may preclude solids disposal at the ERDF.

Removal of the OIER from the sludge prior to contact with the acid solution will solve these two problems. A first analysis of the required separation efficiency has shown that it is necessary to remove $95 \%$ of the resins prior to sludge dissolution and to limit the sludge entrained with the resins to less than $5 \%$ to allow disposal at the ERDF.

\subsection{Properties of the Solids}

In order to identify processes for separating the resin from the sludge (K East basin floor and weasel pit sludge), the properties of the different solids need to be reviewed and understood. A discussion of key solids properties is presented below.

\subsubsection{Particle Size}

Figures 1-1 and 1-2 present the particle size distribution of the anionic and cationic resins.

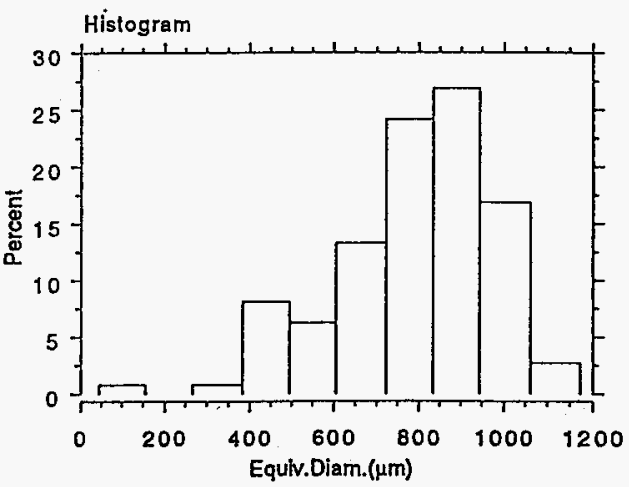

Figure 1-1. Particle Size Distribution of Anionic Resins 
HNF-3128, Rev. 0

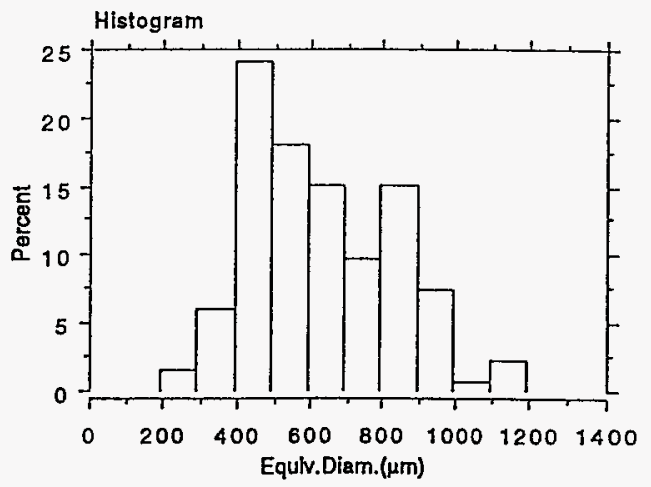

Figure 1-2. Particle Size Distribution of Cationic Resins

As shown by these curves the resin bead diameters range between 200 and $1200 \mathrm{um}$.

Particle size distributions have been measured on sieved samples (about 700 um mesh) for the $\mathrm{K}$ East basin floor sludge and/or weasel pit sludge samples. Figure 1-3 shows the particle size distribution for the $\mathrm{K}$ East Basin floor sludge.

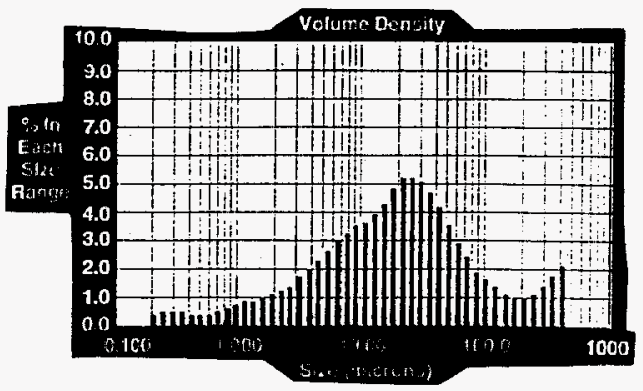

Figure 1-3. Particle Size Distribution for KE Floor Sludge 
HNF-3128, Rev. 0

Figure 1-3 also shows that the particle size varies from 0.1 to $700 \mathrm{um}$. Moreover, it has been shown that the percentage of material above 700 um varies from less than $1 \%$ for the Weasel pit sludge to about $15 \%$ for the floor sludge.

\subsubsection{Particle Density}

The K East basin floor sludge and weasel pit sludge consists mainly of the following components (Pearce 1998).

- Iron oxides

- Aluminum oxides

- Uranium oxide

- Uranium

- Silica

The density of the different compounds are provided in Table 1-1.

Table 1-1. Densities of Compounds in the K East Basin Floor Sludge and Weasel Pit Sludge

\begin{tabular}{|l|l|}
\hline \multicolumn{1}{|c|}{ Compound } & \multicolumn{1}{c|}{ Density $\left(\mathrm{Kg} / \mathrm{m}^{3}\right)$} \\
\hline $\mathrm{Fe}_{2} \mathrm{O}_{3}$ & 5240 \\
\hline $\mathrm{Al} 2 \mathrm{O} 3$ & 3970 \\
\hline $\mathrm{UO} 2$ & 10960 \\
\hline $\mathrm{U}$ & 19050 \\
\hline $\mathrm{SiO} 2$ & 2640 \\
\hline $\mathrm{NRW} 100$ & 1240 \\
\hline $\mathrm{NRW} 400$ & 1070 \\
\hline
\end{tabular}

\subsubsection{Other Characteristics of the Solids}

Two additional properties that may be useful in identifying a potential separation process are the spherical shape of the resin beads and the magnetic nature of the iron compounds. 
HNF-3128, Rev. 0

\subsubsection{Conclusions on the Solids Properties}

The above data suggests two main resin properties that should be considered in identifying a separation process. These properties are:

- the resins have the lowest density and

- the resins are large particles compared to the vast majority of the sludge components.

\subsection{Mechanisms and Technologies for Organic Ion Exchange Resins Separations}

Taking into account the identified resins properties, three different principles can be considered for the separation of the resins.

1. Screening - which is based on size and shape of the particles.

2. Sedimentation - which is based on size, shape, and density of the particles.

3. Flotation - which is based on density only

\subsection{Screening}

Screening is the process of separating particles into groups that contain only particles of a specific size range (i.e, defined maximum and minimum size limits). The size of a non-uniform particle cannot be readily defined, but it can be described in terms of a surface opening through which that particle size will barely pass or not pass. That is, two openings, the smaller of which will retain all the fragments of the size group and the larger of which will pass all fragments, will define a size range.

A screen appears to be a simple piece of equipment, however, it is based on many complex features. The main function of a sizing screen is to separate undersize material from a feed, whatever the range of material sizes in the feed, by allowing the undersized material to pass through the apertures in the screen. This separation must be achieved as a stated efficiency and at a given feed rate. The construction must be sufficiently robust for the designed function and the screening operation must provide a suitable mode of transportation so as to allow separation to be achieved most effectively. From an operational standpoint, the screen should function without producing excessive spillage or causing degradation of the material during transportation.

The objective of a screen, is to accept a feed containing a mixture of particles of various sizes and separate it into two fractions, an underflow that is passed through the screen and an overflow that is rejected by the screen. Either stream may be the desired product.

An ideal screen would sharply separate the feed mixture in such a way that the smallest particle in the overflow would be just larger than the largest particle in the underflow. This ideal separation 
defines a cut diameter, $D_{p c}$ that marks the point of separation between the fractions. Usually $D_{p c}$ is chosen to be equal to the mesh opening of the screen.

Actual screens do not give a perfect separation about the cut diameter, rather the undersize contains about $19 \%$ of material coarser than the $D_{p c}$ and the oversize contains about $15 \%$ that is smaller than $D_{p c}$. The closest separations are obtained with spherical particles on standard testing screens, however, there is still an overlap. The overlap is pronounced when the particles are needlelike or fibrous or where they tend to aggregate into clusters that act as large particles. Some long thin particles may strike the screen surface endwise and pass through. Other particles of the same size and shape may strike the screen sidewise and be retained. Commercial screens usually give poorer separations than testing screens of the same mesh opening operating on the same mixture.

The capacity of a screen is controlled simply by varying the rate of feed to the unit. The effectiveness obtained for a given capacity depends on the nature of the screening operation. The overall passage of a given undersize particle is a function of the number of times the particle strikes the screen surface and the probability of passage during a single contact. If the screen is overloaded, the number of contacts is small and the probability of passage is reduced by the interference of other particles. The improvement of effectiveness attained at the expense of reduced capacity is a result of more contacts per particle and better probability for passage on each contact.

The probability of passage of a particle through a screen depends on:

- The fraction of the total surface represented by openings,

- The ratio of the diameter of the particle to the width of an opening in the screen, and

- The number of contacts between the particle and the screen surface.

When all of the above factors are constant, the average number of particles passing through a single screen opening in unit time is nearly constant, independent of the size of the screen opening. If the size of the largest particle that can just pass through a screen is $\mathrm{D}_{\mathrm{pc}}$, then for a series of screens of different mesh sizes, the number of openings per unit screen area is proportional to $1 / \mathrm{D}_{\mathrm{pc}}{ }^{2}$. The mass of one particle is proportional to $\mathrm{D}_{\mathrm{pc}}{ }^{3}$. The capacity of the screen in mass per unit time is proportional to $\left(1 / \mathrm{D}_{\mathrm{pc}}{ }^{2}\right)\left(\mathrm{D}_{\mathrm{pc}}{ }^{3}\right)=\mathrm{D}_{\mathrm{pc}}$. Then the capacity of a screen, in mass per unit time, divided by the mesh size should be constant for any specified conditions of operation. This concept is a practical "rule of thumb". In actuality, capacities of actual screen, in ton $/ \mathrm{ft}^{2}$-h-mm mesh size normally range between 0.2 to 0.8 for vibrating screens. As the particle size is reduced, screening becomes progressively more difficult. 
HNF-3128, Rev. 0

\subsubsection{Applicability of Screening to the Separation between Sludge and Organic Ion Exchange Resins}

As indicated in Section 1.2.1, the particle size distribution of the sludge is much wider than the particle size of the OIER. Technologies based on screening are applicable to the resins and to the sludge but alone will not be able to separate the resins from the other solids.

\subsubsection{Screening Technologies}

There is a tremendous amount of technologies that have been developed for the screening of materials and it is beyond the scope of this engineering study to review all the available technologies and to choose one technology.

Beyond the different type of screens (size, shape, type of aperture...), the main options that exist for the screening technologies are:

- Fixed screens or moving screens (rotating or vibrating) and

- Solids removal from the surface of the screen (gravity, mechanical, or back flushing)

Fixed screen technologies may present several drawbacks such as:

- solids build-up (caking) may occur very quickly,

- the pressure drop across the screen may be high, and

- the cleaning of the screen may require large amounts of liquid for backwashing.

However, fixed screen technologies are simple and more adapted to a nuclear environment.

\subsubsection{Recommendation for Screening Technologies}

Fixed screen technology is recommended for use in processing $\mathrm{K}$ Basin sludge. However, it is necessary to perform some testing to select a screen that can be used to overcome the drawbacks that have been mentioned previously.

The main objectives of that testing will be to determine the appropriate screen characteristics (e.g., material, shape, size, slope), optimize the washing of the solids on the screen to remove the small particles, and optimize the removal of the solids from the screen (probably by a combination of back flushing and gravity).

A vibrating screen may be considered if a simple fixed screen proves unsuitable. 
HNF-3128, Rev. 0

\subsection{Sedimentation Based Technologies}

Separation by sedimentation is based on size, shape, and density. The main characteristic involved in this type of process is the relative terminal velocities or settling rates of particles through a fluid, either moving or motionless. Two types of sedimentation process can be envisaged - gravity sedimentation and centrifugal sedimentation

\subsubsection{Gravity Sedimentation}

Gravity sedimentation is process for solid-liquid separation due to gravitational forces. Differences in density between the solids and the suspending liquid is necessary. Gravity sedimentation is highly dependent on the settling velocities of the solid particles.

\subsubsection{Settling Velocity}

For a given particle (size, density) the settling velocity of the particle in a given fluid (viscosity, density) is defined by the following expression:

$$
V_{s}=\left\{4 / 3\left(g\left(\delta_{p}-\delta_{w}\right) d_{p}\right) / C_{D} \delta_{w}\right\}^{0.5}
$$

With $C_{D}$ defined by:

$$
C_{D}=24 / N_{R}+3 /\left(N_{R}\right)^{0.5}+0.34
$$

Where $\mathrm{N}_{\mathrm{R}}$ designates the Reynolds number.

The other constants are:

$$
\begin{aligned}
& \mathrm{V}_{\mathrm{s}}=\text { particle settling velocity, } \mathrm{m} / \mathrm{s} \\
& \delta_{\mathrm{p}}=\text { density of particle, } \mathrm{kg} / \mathrm{m}^{3} \\
& \delta_{\mathrm{w}}=\text { density of water, } \mathrm{kg} / \mathrm{m}^{3} \\
& \mathrm{~g}=\text { acceleration due to gravity, } \mathrm{m} / \mathrm{s}^{2} \\
& \mathrm{~d}_{\mathrm{p}}=\text { diameter of particle, } \mathrm{m}
\end{aligned}
$$

(Appendix A details how these expressions has been derived.)

Figure 2-1 shows the variation of the terminal settling velocity as a function of the particle size for different type of solids (from resins to uranium). 


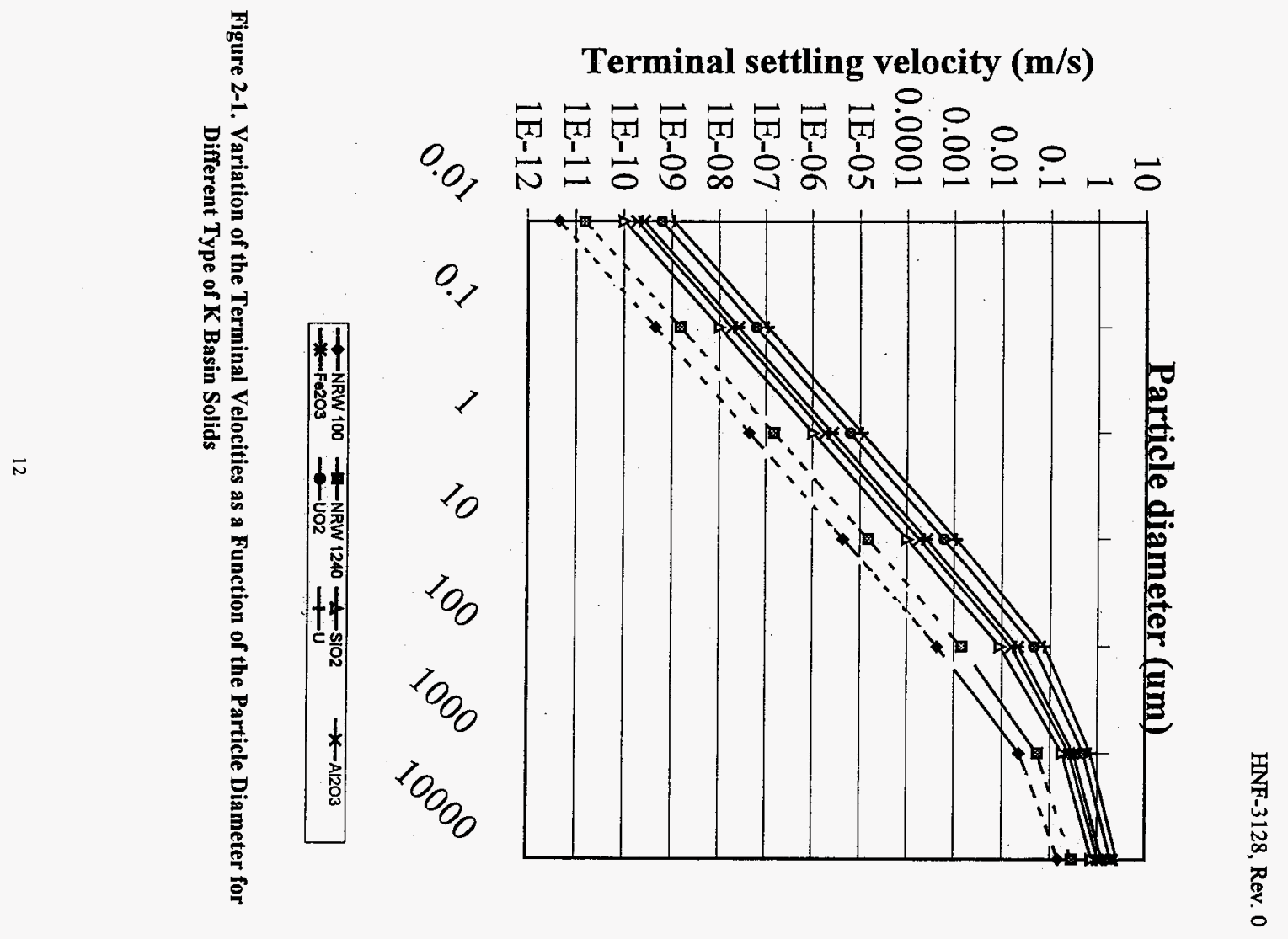


HNF-3128, Rev. 0

\subsubsection{Applicability Gravity Sedimentation}

Figure 2-1 shows clearly that the settling velocities of the OIER is lower (for a given particle diameter) than the settling velocity of a sand or uranium oxide particle with the same diameter. However, the figure also shows that for a given settling velocity, sand or uranium oxide particles with a smaller particle diameter can settle with a velocity identical to some resin particles.

So it appears unlikely that separation of the OIER from the sludge can be achieved by using technologies based only on sedimentation in natural gravitational field.

\subsubsection{Gravity Sedimentation Based Technologies}

Several types of gravity sedimentation technologies are discussed in the following sections.

\subsection{Settling Basin}

For the settling of discrete particles, the removal efficiency is related directly to the settling velocity and not to the depth of the basin. Sedimentation basins should be constructed as shallow as possible to optimize removal efficiency. Although this approach is correct theoretically, there are numerous practical considerations that limit the use of extremely shallow basins. The sedimentation is predicated upon the overflow rate, or critical velocity. The overflow rate yields a parameter termed the critical settling velocity $\left(\mathrm{V}_{\mathrm{w}}\right)$ which is a function of the tank geometry, hydraulic detention time, and the volumetric flow rate. Particles will have an assigned (due to their size, shape, and density) a settling velocity ( $\left.V_{s}\right)$. For particles to be removed within the settling tank, the particles must have a settling velocity greater than the critical settling velocity.

However, particles having a settling velocity less than the critical velocity, will be removed in the proportion $\mathrm{V}_{\mathrm{s}} / \mathrm{V}_{\mathrm{sc}}$. Therefore, the critical settling velocity becomes an important design parameter.

\subsection{Lamella Settler}

The tube and lamella settlers are sedimentation units designed to follow ideal theory more closely. They are constructed of bundles of tubes or plates set at selected angles to the horizontal. As such, these settlers have a very short settling distance and the effects from circulation is damped because of the small size of the tubes. Tube sizes are 25 to $50 \mathrm{~mm}$ and when the imposed angle is greater than $45^{\circ}$ the solids tend to slide out of the tube due to gravitational force.

Tube and lamella settlers have been developed as an alternative to shallow basins and are used in conjunction with both existing and specially designed sedimentation basins. Tube and lamella settlers are shallow settling devices consisting of stacked off-set trays or bundles of small plastic tubes of various geometries. They are used to enhance particle settling characteristics. 
The shape, hydraulic radii, angle of inclination, and length of the plate and tube settlers will vary according to the particular application. The flow passes upward through the tube or lamella settlers and exits from the top. The solids that settle out within the settlers move by means of gravity in a counter current manner downward and out. To enable these settlers to be self-cleaning, they are set at an angle between 45 and $60^{\circ}$ from the horizontal. When the angle is greater than $60^{\circ}$, the efficiency decreases. If the settlers are less than $45^{\circ}$, sludge particles will tend to accumulate within the settlers and reduce efficiency.

\subsection{Elutriation}

In this mechanism, the superficial velocity is greater than the settling velocity of a particle or particles, with the overall effect of transporting the particles in an upflow configuration. As can be determined from Figure 2-1, the resin particles have terminal settling velocities of approximately $4 \mathrm{E}-04$ meters per second to approximately $6 \mathrm{E}-02$ meters per second (resin diameter is varying between 200 and 1200 microns).

Elutriation operations may either be as a three component flow (liquid, gas, and solid) or a two component flow of liquid and solid. The term fluidization may be used to designate the fluid-solid contact process in which a bed of finely divided solid particles is lifted and agitated by a stream of process fluid. At the lower end of the velocity range, the amount of lifting is slight, the particles behaving like quicksand, a "teetering bed". At the other extreme, the particles are in full suspension and are carried along with it.

If a bed of particles is not restricted and a sufficiently high fluid velocity is introduced, and the pressure drop (resistance to flow) is equal to or greater than the weight of the particles, the particles will be lifted. Since the particles are not bonded together and rest upon themselves, they will move farther apart and open up the interstices to allow easy passage of the fluid. Therefore, the bulk density decreases and the bed expands in volume. At velocities great enough to give a pressure drop equal to the weight of particles in a bed per unit area of tube cross section, the bed expands so that all the particles are no longer in contact and the particles are now in the fluid state. Further increase in velocity is accompanied by a further increase in bed expansion or voidage. As the superficial velocity is increased, the particles will be carried up the tube to be subsequently flushed out into a receiving container.

\subsubsection{Centrifugal Sedimentation}

Centrifugation increases the mass forces on particles and extends sedimentation of finer particles sizes and emulsions that are normally stable in a gravity field. Equipment available for centrifugal sedimentation are typically divided into fixed-wall devices (hydrocyclones) and rotating wall devices (sedimenting centrifuges). 
HNF-3128, Rev. 0

\subsubsection{Separation of Particles in Induced Gravitational Field}

Sedimentation for the removal or concentration of particles in a liquid by induced gravitational field (e.g. Hydrocyclones), causes the particles to migrate through the fluid radially toward or away from the axis of rotation, depending upon the density differences between the particles and the fluid. If there is no density differences or if the differences are negligible, separation by an induced gravitational field will not be achieved. As particles move radially outwards they are continuously accelerated $\left(R w^{2}, R=\right.$ radius of the particle position, $w=$ the angular speed).

Particle motion is no longer at constant velocity, but as the particles move radially outwards, they are continuously accelerated ( $\mathrm{Rw}^{2}$ increases).

In order to identify the parameters that influence the separation of particles in processes using induced gravitational field, it is interesting to use equations that have been established for hydrocyclones by Trawinski (1977). In particular, Trawinski has shown that the diameter of the smallest particle leaving in the underflow (implicit is the larger particles also are in the underflow) is given by the following expression:

$$
d_{s}=\left\{(18 \mu q) / g\left(\delta_{p}-\delta_{f}\right) Z^{\prime}\right\}
$$

where: $\mathrm{d}_{\mathrm{s}}=$ smallest particle leaving in the underflow

$$
\begin{gathered}
\mu=\text { Viscosity } \\
q=\text { volume flow rate/unit area }=Q / A \\
Q=m^{3} / \text { hour } \\
A=\pi D_{0} L \\
L=\text { vortex finder clearance length } \\
\delta_{p}=\text { density of particle }
\end{gathered}
$$

And $Z$ ' is the geometric mean acceleration factor and is given by the following equation:

$$
Z^{\prime}=\left(2 V_{0}^{2} / g\right)(D)
$$

where $\mathrm{V}_{\mathrm{o}}=\max$ tangential velocity at the air core

$$
\begin{gathered}
=V_{f}\left(D / D_{o}\right) \\
V_{f}=\text { feed inlet velocity } \\
D=\text { diameter of the cyclone cylinder } \\
D_{0}=\text { vortex finder diameter } \\
g=\text { gravity constant }
\end{gathered}
$$


HNF-3128, Rev. 0

\subsubsection{Applicability of Centrifugal Sedimentation}

These equations show clearly that for a given design of a separation process based on induced gravitational field (e.g. geometry of the cyclone, flow rate), the behavior of the particles is a function of their size and their density.

So, it appears impossible to achieve the separation of the OEIR from the sludge by using technologies based only on sedimentation in an induced gravitational field.

\subsubsection{Centrifugal Based Technologies}

As stated earlier, equipment available for centrifugal sedimentation are typically divided into fixed-wall devices (hydrocyclones) and rotating wall devices (sedimenting centrifuges).

\subsection{Hydrocyclone}

Cyclones have found wide application in various fields of technology. Some applications are used for solid-liquid separation and as such are referred to as hydrocyclones or hydroclones. The basic separation principle employed in cyclones is centrifugal sedimentation, that is, the suspended particles are subjected to centrifugal acceleration, which allows separation from the fluid. Unlike centrifuges, hydroclones have no moving parts and the required vortex motion is performed by the fluid itself.

Figure 2-2 shows a cross-section of a hydroclone of conventional design. It consists of a cylindrical section joined to a conical portion. The suspension of particles in a liquid is injected tangentially through the inlet opening in the upper part of the cylindrical section and as a result of the tangential entry, a strong swirling motion (vortex) is formed within the cyclone. A portion of the liquid containing the fine fraction of particles is discharged through the outlet by a cylindrical tube fixed in the center of the top and projecting some distance into the cyclone (overflow tube or vortex finder). The remaining liquid and the coarse fraction of the material leave through a circular opening at the apex of the cone (underflow orifice). 
HNF-3128, Rev. 0

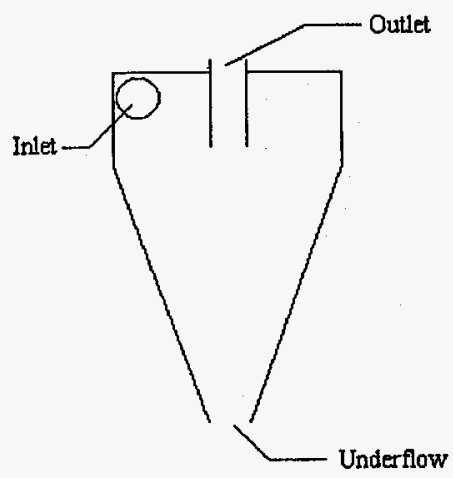

Figure 2-2. Cross-Section of a Hydroclone

There are several advantages to the hydroclones.

- The are extremely versatile in application in that they can be used to clarify liquids, classify solids, concentrate slurries, or sort solids according to density or shape.

- They are simple, inexpensive to purchase, install and operate, requiring little in the areas of maintenance and support structures.

- They are small relative to other separators, therefore saving space. They also give low residence times, which is an advantage in terms of speed of control over the sedimentation classifiers.

- The existence of high shear forces in the flow is an advantage in classification of solids because it breaks any agglomerates, and also in the treatment of thixotropic and Bingham plastic slurries. 
HNF-3128, Rev. 0

The main disadvantages of hydroclones are:

- They are somewhat inflexible once installed and operated, giving low turndown ratios due to the strong dependence of their separation performance on flowrate and feed concentration. They are also inflexible due to their general sensitivity to fluctuations in feed flowrate and solids concentration.

- There are limitations on their separation performance in terms of sharpness of cut, range of operating cut size, de-watering performance or clarification power. Some of these characteristics may be improved in multi-stage arrangement, but at addition costs of power and investment.

- They are susceptible to abrasion, but this can be mitigated with materials of construction.

- The existence of shear may sometimes turn into a disadvantage because flocculation cannot be used to enhance the separation as in the case of gravity thickeners.

\subsection{Centrifuges}

A sedimenting centrifuge consists of an imperforate bowl into which a suspension is fed and rotated at high speed. The liquid is removed through a skimming tube or over a weir while the solids either remain in the bowl or are intermittently or continuously discharged from the bowl. Five main types of industrial sedimenting centrifuge may be distinguished according to the design of the bowl and of the solids discharge mechanism. The main design parameters of a centrifuge are the internal radius, bowl height, bowl rotation, and feeding rate. Figure 2-3 shows a schematic classification of the equipment.

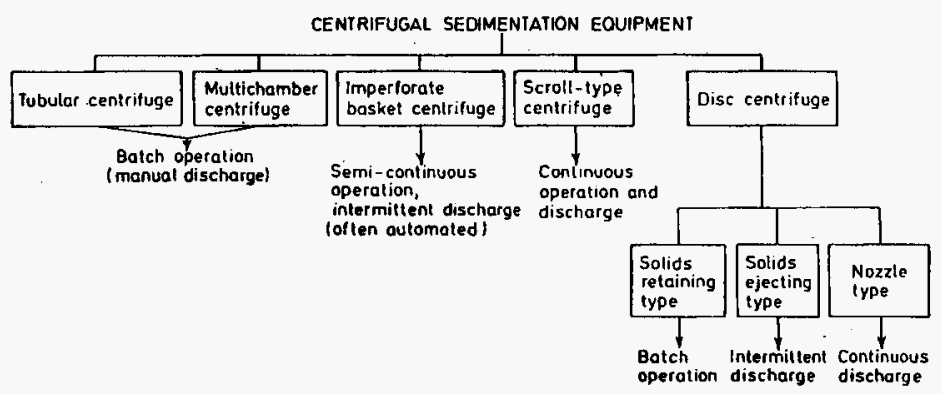

Figure 2-3. Classification of Centrifugal Sedimentation Equipment 
HNF-3128, Rev. 0

Centrifuges are a complex piece of equipment but they have been used extensively in nuclear environments and especially in reprocessing plants (La Hague, Sellafield, Purex...) to separate solids from dissolution liquors.

\subsubsection{Recommendation for Sedimentation Based Technologies}

Table 2-1 summarizes the main advantages and drawbacks of the different technologies for separation of particles with different size and/or density.

Table 2-1. Advantages and Drawbacks of Different Sedimentation Based Technologies

\begin{tabular}{|c|c|c|}
\hline Technologies & Advantages & Drawbacks \\
\hline Settling tank & $\begin{array}{l}\text { Simple technology } \\
\text { No moving parts } \\
\text { Experience in nuclear } \\
\text { applications }\end{array}$ & $\begin{array}{l}\text { Large tanks are necessary } \\
\text { Inventory of solids may be difficult to } \\
\text { control and complicate criticality } \\
\text { management }\end{array}$ \\
\hline Lamellar settler & Compact technology & $\begin{array}{l}\text { Not easy to clean } \\
\text { Inventory of solids may be difficult to } \\
\text { control and complicate criticality } \\
\text { management }\end{array}$ \\
\hline $\begin{array}{l}\text { Elutriation } \\
\text { columns }\end{array}$ & $\begin{array}{l}\text { Simple technology } \\
\text { Inexpensive }\end{array}$ & $\begin{array}{l}\text { Need to control accurately the flow rate } \\
\text { in the column }\end{array}$ \\
\hline Hydrocyclones & $\begin{array}{l}\text { Compact } \\
\text { Experience in nuclear } \\
\text { applications } \\
\text { Inexpensive } \\
\end{array}$ & $\begin{array}{l}\text { Inflexible } \\
\text { Sensitive to feed flow rate }\end{array}$ \\
\hline Centrifuges & Experience in nuclear application & Expensive \\
\hline
\end{tabular}

Based on this comparison, it is recommended that elutriation columns be used if a sedimentation based process is necessary. 
HNF-3128, Rev. 0

\subsection{Flotation}

Two types of flotation mechanisms were considered for separating the OIER from K Basin sludge.

\subsubsection{Flotation Mechanism}

The first flotation principle that can be envisaged is based on the flotation of solids resulting from the increase of the liquid density. In the Section 1.2.2, it has been shown that the OIER density is significantly different (1.07 and 1.24) from the density of the other solids (between 2.64 and 19).

Tests in which the mixed resin was contacted with $10 \mathrm{MHNO}_{3}(\rho \simeq 1.30 \mathrm{~g} / \mathrm{mL})$ showed that both resin types sank though the anion resin showed buoyancy in swirling (Bredt et al. 1998). Segregation of floating anion from cation resin occurred upon contact with concentrated $\mathrm{HNO}_{3}$ which has a density of about $1.46 \mathrm{~g} / \mathrm{mL}$ (Pool et al. 1998). Shrinkage of anion resin is known to occur on contact with strong nitric acid (Ryan 1972).

The second principle that can be envisaged is air-assisted flotation. This process is based on the generation of air (or other gas) bubbles within the slurry and attachment of the solids on to the bubbles. The solids are then transported to the surface through buoyancy and scraped off. Flotation has been used in mineral separation and it has been shown that density and size of the particles are again the main parameters that influence the efficiency of the process. As this mechanism is similar (in its separation performances) to the sedimentation mechanism, it will not be discussed any further.

\subsubsection{Applicability of Flotation}

In theory, it appears very simple to separate the OIER from the sludge. It is just necessary to increase the density of the liquid above 1.24 . If such a liquid can be found, the separation can be very simple. 


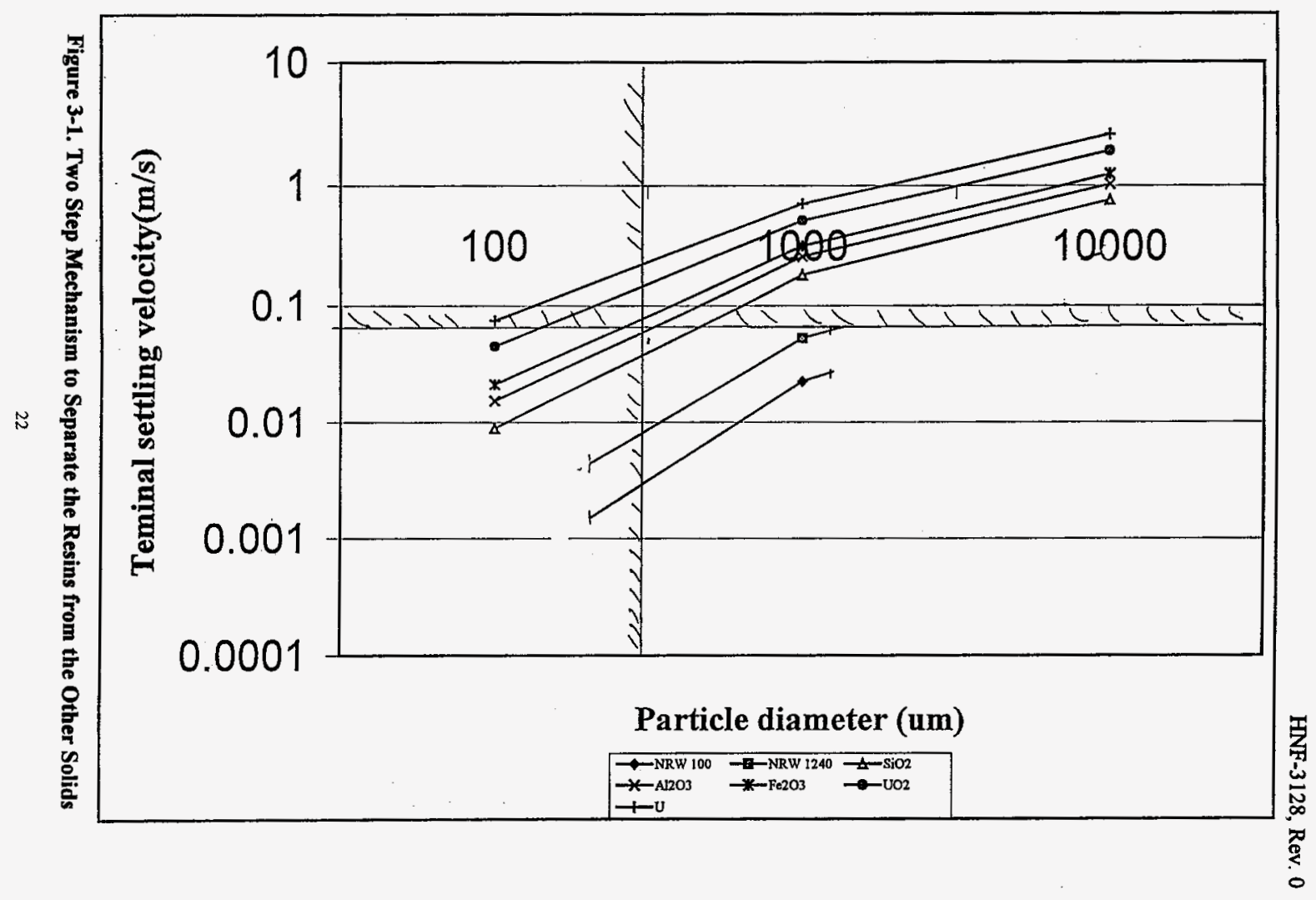


HNF-3128, Rev. 0

In order to implement a flotation process, it is necessary to increase the density of the liquid above 1.24. Two options were considered.

1. Removal of water and use of a non-aqueous solvent. This alternative is not practical as complete dewatering of the slurry, flotation of the resins beads, and removal of the non-aqueous solvent from the resins and the sludge would be necessary.

2. Addition of a chemical component. This alternative is not practical because it was not possible to find a chemical component that would have no significant reactivity with the sludge (this eliminates concentrated nitric acid solution) and no impact on the dissolution process or on the Tank Waste Remediation System acceptance criteria (this eliminates chloride salts).

As such, it was not possible to identify an acceptable method for increasing the density of the liquid, the two step mechanism is recommended even if screening equipment and sedimentation equipment are necessary.

\subsection{Separation Technology}

It is a recommended that a fixed screen ( 300 micron aperture) be used for the separation of the large particles. Small particles should be directed to the dissolver. Further separation of the large particles should be achieved with an elutriation column with an upward water velocity adjusted to lift "only" the OIER. The recommendation for these technologies is based on the discussions on the separation principle (Section 3.1) and on the recommendation of technologies that are detailed in the Sections 2.1.4 and 2.2.3.

\subsection{References}

Bogert, S. R. and J. R. Weber, American Nuclear Society Spring Symposium, pp 586- 592, March 29, 1987.

Davidson, J. F. and B. O. G. Schuler, Trans. Inst Chem. Engrs., Vol 38, pp. 144-154 and 335342,1960 , in Wallis.

Duncan, J. B., Sludge Simulant for Organic Ion Exchange Resin Separation, 8C720-98-JBD001, April 1998.

Filtomat Technical Brochure, 1989.

Flament, T. A., Testing Strategy to Support the Developpment of K Basin Sludge Treatment Processs, HNF-2574, Rev. 0, April 1998.

Haberman, W. L. and R. K. Morton: David W. Taylor Model Basin Rept. 802, 1953, in Wallis. 
HNF-3128, Rev. 0

Hadamard, J., Compt. Rend. Acad. Sci. Paris, Vol 152, pp 1735-1738, 1911, in Wallis.

Jackson, R., Chem Eng, Vol 42, pp. 107- 118, May 1964, in Wallis.

Kato, H. T. Miyazawa, S. Timaya, and T. Iwaski, A Study of and Air-Lift Pump for Solid Particles, Bull of the JSME, Vol 18, No. 117, March 1975.

Kutateladze, S. S. and M. A. Styrikovich, "Hydraulics of Gas-Liquid Systems", Moscow, Wright Field trans. F-TS-9814/V, 1958, in Wallis.

Makenas, B., Editor, Analysis of Sludge from Hanford K East Basin Floor and Weasel Pit, WHC-SP-1182, April 1996.

Moore, T. L., Design, Fabrication, Assembly, and Testing of a Mobile Sediment Processor (MSP) for Processing Sediment in the 100N Fuel Storage Basin, WHC-S-2150, December 1988.

Pearce, K. L., S. C. Klimper, and T. A. Flament, 1998, 105-K Basin Material Design Basis Feed Description for Spent Nuclear Fuel Project Facilities, Volume 2, SLUDGE, HNF-SD-SNF-TI009, Volume 2, Revision 2, Numatec Hanford Corporation, Richland, Washington.

Peebles, F. N. and H. J. Garber Chem Eng. Progr., Vol 49, pp 88-97, 1953, in Wallis.

Perry, R.H. and D. Green, Perry's Chemical Engineers' Handbook, 6th Ed., McGraw-Hill, New York, NY, 1984.

Rybczynski, W., Bull. Acad. Sci. Cracovie, Vol A, pp 40-46, 1911, in Wallis.

Siemes, W. and J. Kaufmann, Chem Eng. Sci., Vol 5, pp. 127-139, June 1956, in Wallis.

Spells, Trans. Inst. Chem. Eng. (London), Vol 33, pp 79-84, 1955, in Perry's.

Svarovsky, L., Hydrocyclones, Technomic Publishing Co, Inc., London, 1984.

Tchobanoglous, G. and F. Burton, Wastewater Engineering, Treatment, Disposal and Reuse, 3rd Ed. McGraw-Hill, New York, NY, 1991.

Tchobanoglous, G. and E. Schroeder, Water Quality - Characteristics, Modeling, Modification, Addision-Wesley, Menlo Park, CA, 1987.

Trawinski, H., Hydrocyclones in Solid/Liquid Separation Equipment Scale-Up, Derek B. Purchas, editor. Uplands Press Ltd., 1977.

Wallis, G. B., One-Dimensionsl Two-Phase Flow, McGraw-Hill, New York, NY, 1969. 
HNF-3128, Rev. 0

Witwer, K. S., Organic Ion Exchange Resin Separation Methods Evaluation, HNF-2729, April 1998. 
HNF-3128, Rev. 0

\section{APPENDIX A}

\section{CALCULATION OF SETTLING VELOCITIES}

\section{Sedimentation Theory}

Conceptually, sedimentation operations are simple. In the idealized system, particles move horizontally with the flow and vertically under gravitational forces. Interaction between particles does not occur in ideal discrete particle settling. Therefore, a mass balance can be written for a discrete particle:

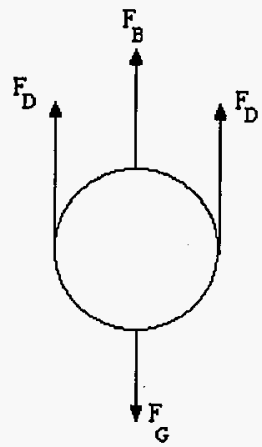

Figure A-1. Settling Spherical Particle

The mass balance is:

EQN A-1

$m_{p} d V_{z} / d t=F_{G}-F_{B}-F_{D}$

where:

$$
\begin{aligned}
& \mathrm{m}_{\mathrm{p}}=\text { mass of settling particle, } \mathrm{kg} \\
& \mathrm{V}_{\mathrm{B}}=\text { particle settling velocity, } \mathrm{m} / \mathrm{s} \\
& \mathrm{F}_{\mathrm{G}}=\text { gravitational force, } \mathrm{N} \\
& \mathrm{F}_{\mathrm{B}}=\text { buoyant force, } \mathrm{N} \\
& \mathrm{F}_{\mathrm{D}}=\text { drag force, } \mathrm{N}
\end{aligned}
$$

The net gravitational force is given by:

EQN A-2

$$
F_{G}-F_{B}=\left(\delta_{p}-\delta_{w}\right) g V_{p}
$$


HNF-3128, Rev. 0

where:

$\delta_{\mathrm{p}}=$ density of particle, $\mathrm{kg} / \mathrm{m}^{3}$

$\delta_{\mathrm{w}}=$ density of water, $\mathrm{kg} / \mathrm{m}^{3}$

$\mathrm{g}=$ acceleration due to gravity, $\mathrm{m} / \mathrm{s}^{2}$

$\mathrm{V}_{\mathrm{p}}=$ volume of particle $\left(11 \mathrm{~d}_{\mathrm{p}}^{3} / 6\right), \mathrm{m}^{3}$

$\mathrm{d}_{\mathrm{p}}=$ diameter of particle, $\mathrm{m}$

The drag force is a function of the cross-sectional area of the particle, the settling velocity of the pqrticle, the liquid density and the coefficient of drag:

EQN A-3

$$
F_{D}=C_{D} A_{p} \delta_{w}\left(V_{t}^{2} / 2\right)
$$

where:

$C_{D}=$ coefficient of drag

$A_{P}=$ cross-sectional area of particle $\left(\Pi d^{2}{ }_{p} / 4\right), m^{2}$

$\delta_{w}=$ density of water, $\mathrm{kg} / \mathrm{m}^{3}$

$\mathrm{V}_{\mathrm{s}}=$ particle settling velocity, $\mathrm{m} / \mathrm{s}$

For spherical particles, the coefficient of drag can be estimated using the following relationship:

EQN A-4

$$
C_{D}=24 / N_{R}+3 /\left(N_{R}\right)^{0.5}+0.34
$$

where:

$$
\mathrm{N}_{\mathrm{R}}=\text { Reynolds number, dimensionless }
$$

$$
\begin{aligned}
& =\left(V_{\mathbf{z}} d_{p} \delta_{w}\right) / \mu \\
\mu & =\text { liquid viscosity, } \mathrm{kg} / \mathrm{m} \cdot \mathrm{s}
\end{aligned}
$$

In the ideal system, the terminal settling velocity is attained quickly and the acceleration term can be assumed to be negligible. Therefore, equation 1 can be restated as:

EQN A-5

$$
F_{G}-F_{B}=F_{D}
$$

Substituting equation 2 for $F_{G}-F_{B}$ and equation 3 for $F_{D}$, and solving for the settling velocity, $\mathrm{Vu}_{\mathrm{s}}$, yields:

EQN A-6 $\quad V_{s}=\left\{4 / 3\left(g\left(\delta_{p}-\delta_{w}\right) d_{p}\right) / C_{D} d_{w}\right\}^{0.5}$

When $\mathrm{N}_{R}<0.3$, the first term of equation 4 predominates, and the discrete particle settling rate becomes (Stoke's Law):

EBN A-7

$$
V_{t}=\left(g\left(\delta_{p}-\delta_{w}\right) d_{p}^{2}\right) / 18 \mu
$$




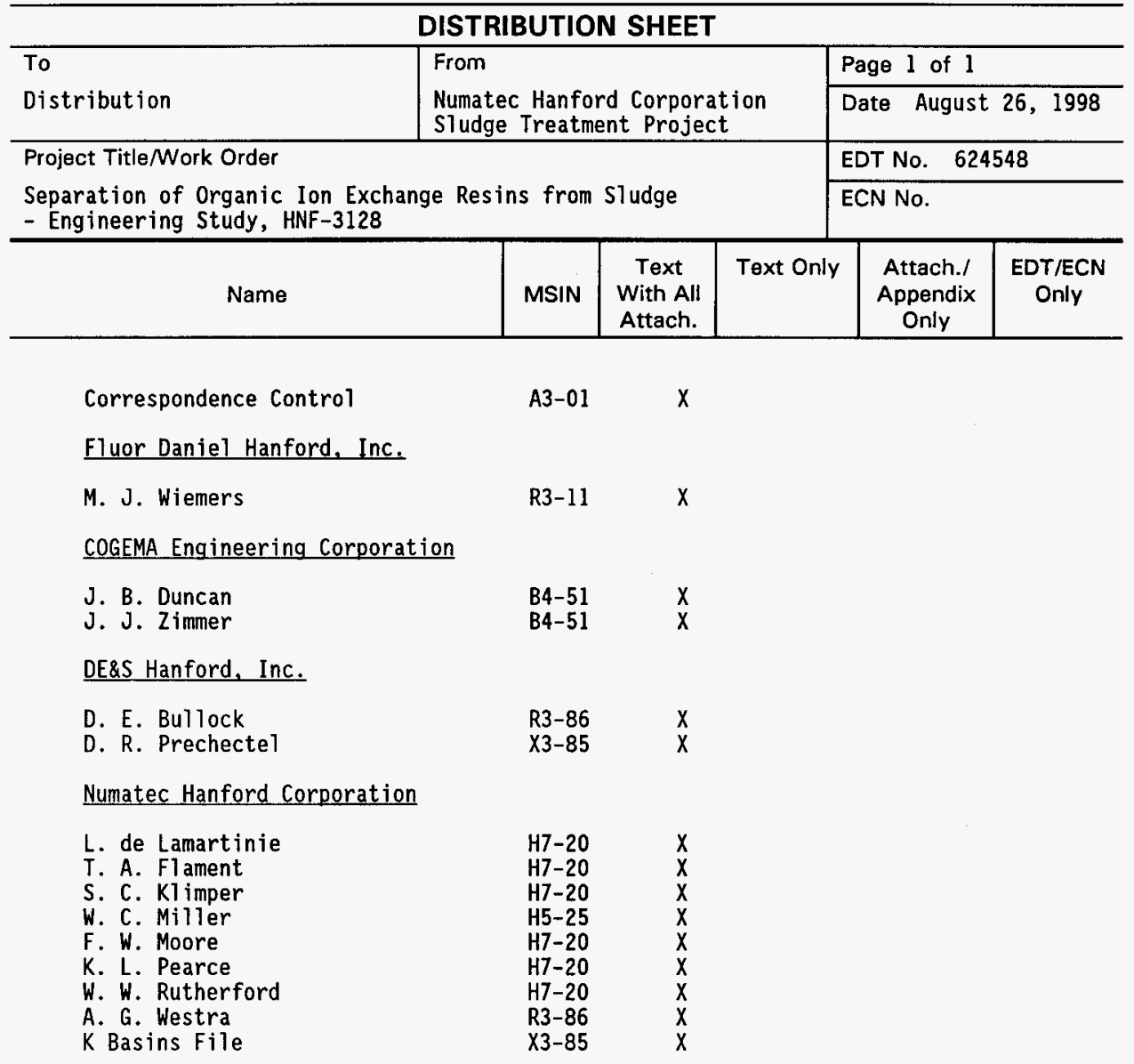

